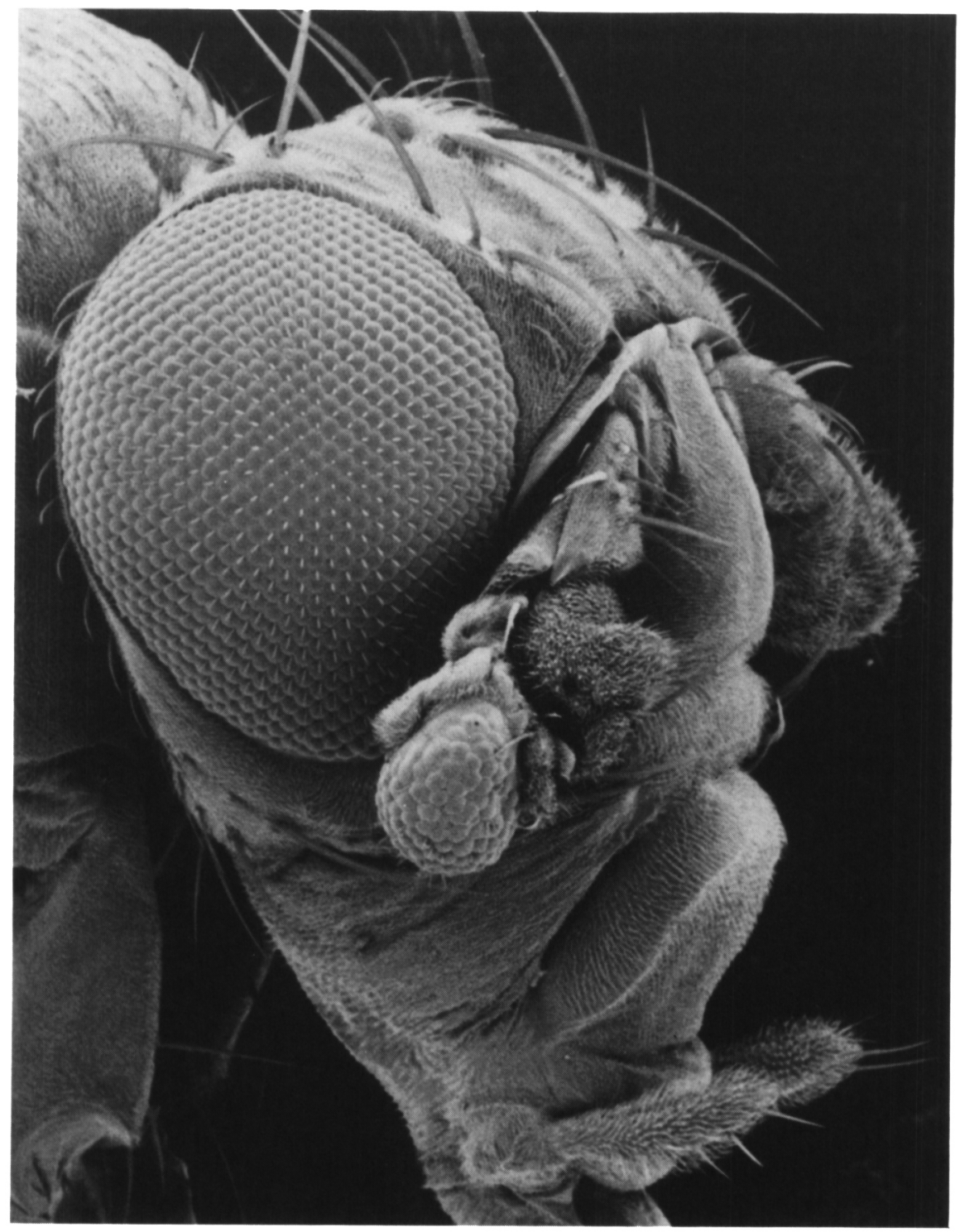

Fig. 1: The consequences of abormal eyeless activation can be seen in these ectopic eyes on the antenna of a fruit fly (Photo: Courtesy of Andreas Hefti and Georg Halder, Biocenter, University of Basel). This picture was reproduced in the majority of newspapers and journals reporting on the experiment. 


\section{FRANKENSTEINIAN KNOWLEDGE?}

\section{Monster flies}

Scientific knowledge is experimental knowledge. Such knowledge can be seen as "forbidden," either because the experiments leading to that knowledge are seen as immoral, or because interventions made possible by that knowledge could be morally offensive. There is currently an interesting case in the realm of genetic engineering, in which moral condemnations have been forthcoming but have not been unanimous. Here I present an analysis of this heterogeneity of moral assessment in the hope that this study of a single case might be helpful for the discussion of bioethical generalizations around the category of the "forbidden."

A team consisting of Walter J. Gehring, Georg Halder and Patrick Callaerts (Biocenter, University of Basel) activated a gene called eyeless in parts of the Drosophila larvae where it is not normally active. As a consequence those parts of the animal grew extra eyes. The experimental flies had eyes on the wings, on the legs, on the antennae or in place of the antennae. Some flies had as many as 14 fully developed eyes (10 additional eyes), each with the hexagonal ommatidia, interommatidial bristles, lenses, and with a normal number and trapezoidal arrangement of the rhabodomeres of photoreceptors that make up the normal structure of a Drosophila eye.

The front page of the International Herald Tribune of March 25-26, 1995 announced this successful genetic induction of ectopic eyes in Drosophila melanogaster with the title " 'Frankensteinian' Fruit Fly Experiments." What is the relation of the category 'Frankensteinian' to that of the 'morally forbidden'? What is the role of popular mythology in the public moral evaluation of scientific research?

The original scientific publication of the experiment had appeared in the journal Science on the previous day. The frontispiece was a scanning electron-micrograph of the Drosophila head with additional facet eyes on 
the tips of its shortened antennae (see Fig. 1). ${ }^{2}$ Dozens of articles in newspapers and broadcast messages spread the obviously sensational story of genetic engineers "combining elements of the sublime and the macabre." 3

What did the experiment show? For the scientists involved it was a test of a scientific hypothesis. For at least some part of the public it was a sign that something is rotten in the state of science. Here are strikingly different perceptions of the same real event. In this paper I want to study this disparity and its consequences. Although the described experiment is a single case, we observe here a situation where the question of "forbidden knowledge" can emerge. I argue that the disparity of perception between scientists and parts of the general public is mediated by parts of different interpretative patterns and that these patterns can be understood adequately only if the level of myth is not excluded. What are the processes which lead to such questions as whether certain possible activities should be excluded from scientific research? Perhaps a clearer understanding of the processes leading to this question will help in coming to terms with the question itself.

\section{Aporia in a Frankensteinian ethic of research}

The most influential version of the Frankenstein story in our century was doubtless the James Whale movie classic Frankenstein of 1931. This film became so popular that the name "Frankenstein" cannot be pronounced today without evoking its echo. ${ }^{4}$ Therefore, it is worth looking more carefully at Whale's version. ${ }^{5}$ In it, Henry Frankenstein is the prototype of a mad scientist with the fanatic ambition to create life. He did not allow even his friends to visit his laboratory because he sensed that his experiments might be violating the boundaries of morality. Together with his assistant, Fritz, he exhumed corpses in the churchyard, and stole parts of hanged criminals, and a brain out of the laboratory of his mentor, Professor Waldman. After combining these parts he bestowed life upon a corpse by means of "chemical galvanism" and "electrobiology." The success intoxicated his mind; he did not respect the warnings of others, and he saw himself in a divine position. Soon afterwards, the warnings of old Waldman came true. The monster, having been brought to life, became aggressive: first, as a consequence of the fact that the assistant, Fritz, had confounded different brain preparations and had taken the brain of a criminal; and second, as a consequence of the fact that the mind of the 
creature had not been able to develop in a normal friendly environment. Fritz tortured him and, because of his appearance, he was hated and regarded with fear by every human being (except the little girl at the lake). The monster murdered Fritz, Waldman (?), the little girl and Elizabeth (?) and was finally destroyed by a mob of citizens (not without a final combat with Frankenstein himself) in a burning windmill.

Against the background of Whale's film, it seems quite easy to define what is meant by the term 'Frankensteinian experiment'. It is an experiment which:

(a) violates moral boundaries. The most serious offence to basically Christian morality is to disregard the ontological difference between man and God, i.e., to commit the sin of pride (hubris).

(b) has possibly fatal consequences for the experimenter and for the wider society,

(c) is such that a prudent society would forbid it.

This concept of Frankensteinian experiment can be interpreted so that a concept of Frankensteinian knowledge is gained, namely as knowledge that is produced by a Frankensteinian experiment. Knowledge of a sort that is obtainable only by immoral experiments could itself be immoral because of its origin and of its character: it is knowledge of how something immoral can be effected. Whale's film provides us with the example of the recombination and animation of dead bodies. The scientist used pre-existing knowledge and applied it in an immoral way. In the course of his trials he refined his methods and obtained results which would have been otherwise unobtainable. The resulting knowledge is at least in part tied inextricably to the realisation of immoral plans. Frankensteinian knowledge would be:

(a) knowledge to which mankind has no right. This knowledge would give to those who possess it a power they should not have, like the knowledge Eve and Adam obtained after eating of the forbidden fruit. Such knowledge contains the dangerous power to change the status of humanity for a worse state,

(b) knowledge, whose use or application might have fatal consequences and which ought to be concealed or destroyed in order to prevent these consequences. 
And therefore:

(c) knowledge that, in the context of pre-existing morality, ought not to be obtained.

Before entering into the discussion of the severe problems that arise in attempting to use this concept of "Frankensteinian knowledge" as the basis of an ethics of scientific research, we should not overlook the basic ambiguity of the moral message of the Frankenstein film: the figure of Henry Frankenstein is fascinating, in spite of his obviously immoral behavior. And perhaps this fascination emerges precisely because of that immorality, and not in spite of it. He has the courage to go beyond traditional boundaries, to break the constraints of a given condition. He is the protagonist of a form of progress that has been constitutive of modern culture since the Enlightenment. He is a real Baconian hero. ${ }^{6}$

I therefore propose that we add a fourth element to our definition of Frankensteinian knowledge:

(d) knowledge that, once obtained, might nevertheless improve the status of humanity in certain respects and might trigger a moral change.

This heroic element of Frankenstein is also latent in the newspaper text cited above. The title in its entirety was: "Science Mimics the Movies-'Frankensteinian' Fruit Fly Experiments Point to Master Gene for Eye Formation." The result of the experiment is exciting. It will not only bring our knowledge of the genetic mechanisms of the development of organs some steps further, but textbooks of evolution will also have to be corrected. This "master control gene," i.e., a gene that switches on the whole cascade of some 2,500 genes of eye development, is found not only in invertebrates such as the fruit fly, but also in vertebrates such as mice and humans, and even in the squid. The similarities are so close that the corresponding mouse gene induces the very same ectopic eyes in Drosophila (fly eyes, not mouse eyes!). These similarities suggest that a primordial eye has evolved only once, taking on manifold shapes and designs during phylogenetic diversification. Yet, scientists had long assumed that the eye has been invented many different times. The article was not an offence to the Gehring group, but a tribute to the importance of their accomplishment. The title 'Frankensteinian' pointed to this 
founding ambivalence of important scientific discoveries: the carrying-out of the experiment is immoral only from the point of view of one part of established traditional morality. The other part praises the breakthrough as heroic.

The difficulties of this "Frankensteinian ethic of scientific research" are obvious. They encompass at least the following four points:

(1) The appeal to a fixed value system as the basis for the prohibition of certain experiments is conservative and includes no reflection on quality or adequateness. It seeks to defend a given social order, and takes this order for granted, leaving no room for dissent or development.

(2) The decision to forbid would have to take place before fatal consequences had occurred. At the same time there is rarely an absolute certainty that consequences will in fact prove fatal. The decision has to be made even though future events remain uncertain, and in the face of many different assessments of the risk involved. The moral rationale of the Frankensteinian science ethic leaves no room for a judicious weighting of the different appraisals of the possible hazard. Moreover, it leaves no room for a political dimension that could lead to a fair collective decision in a process today called "risk communication." 7

(3) The legal force needed to prevent agents from executing certain types of behaviour requires a moral legitimation. And the immorality of given behaviour cannot as such legitimate the use of governmental force to prevent it. The law-in the context of a liberal society-is distinct from the enforcement of morals. ${ }^{8}$ There have to be sufficiently weighty interests to be protected. The goal of preserving the moral integrity of a society is not alone a sufficiently strong criterion for the acceptance of controlling forces that would prevent deviant behaviour. An experiment could of course be prohibited if it involved criminal acts. The experiments of Henry Frankenstein were doubtless criminal: they included the ravishment of human bodies. But Gehring's experiments are clearly not: there are no laws forbidding the genetic manipulation of flies. And I doubt that we could find reasons good enough to legitimate a general criminalization of genetic engineering. Prohibition is itself a social action with moral qualities, and it requires justification of a sort that goes beyond the mere immorality of the action to be forbidden.

An even more serious difficulty is met when it is knowledge that should be forbidden. To be able to formulate a prohibition, someone has 
already to know what is to be forbidden, i.e., the knowledge has in some sense to be anticipated. We cannot forbid a type of knowledge without having a quite precise idea of what the contents of that knowledge would be. This would need to be at least precise enough to enable us to specify why that knowledge would have such and such undesirable effects. This is possible in some cases but not in all. The knowledge of how to animate recombined corpses can be described, but the theory of relativity and its consequences could not have been anticipated.

(4) The ambivalence of the Frankensteinian moral is represented by the plurality of moral assessments encountered. Society does not speak with one voice: some groups might condemn a given experiment, some praise it, and some remain ambivalent.

\section{A myth of modern science}

Since the novel Frankenstein or the Modern Prometheus by Mary Wollstonecraft Shelley was published in 1818, ${ }^{9}$ hundreds of variants have risen; stage versions, (science) fiction stories, films, even comic strips. ${ }^{10}$ Each tells a story around the following plot skeleton:

(a) Frankenstein makes a living creature out of bits of corpses,

(b) the creature turns against him and runs amok."1

Some variants share more similarities than just this core plot structure, but each can nevertheless be regarded as a story in its own right. There are few stories in our time of which nearly every adult has a quite precise idea, although these ideas may differ significantly in details. We are urged to concede that Frankenstein is something like a myth. And this is quite embarrassing, because the programme of modernity seems in principle to leave no room for myths. Modernity understands itself as the overcoming of mythological by rational truth. In the words of Chris Baldick:

Such a thing simply should not exist, according to the most influential accounts of what a 'myth' is. ... Myth is, so the argument goes, exclusively a product of pre-literate cultures, from which the alienated and fragmented modern world of money, books, politics, and above all, scientific rationality is by definition cut off. ... The more this argument rejects the possibility of modern myths, the more, ironically, it becomes one itself. . . 12

The programme of modernity consisted in the ordering of the world and the elimination of ambivalence. ${ }^{13}$ Myths are powerful because they 
can signify different things, because they can take on different shapes and are in this way able to help in providing interpretations where human problems clash. It is not necessary that there be gods and goddesses in myths. A myth is essentially a tale, deeply rooted in a common tradition, formulating common desires, and most importantly serving as a medium through which we perceive as meaningful key situations of the real world. Or, to cite Lévi-Strauss's characterization of the mythological: Poetry cannot be translated without serious distortion, "whereas the mythic value of the myth remains preserved, even through the worst translation." 14 Each translation is in consequence something like an original in its own right. Or better, the distinction between original and derivative has no clear significance. Shelley's version is not to be considered the original and the subsequent versions as its more or less authentic copies. Whale's film is not false or bad because its plot stands only in a very loose relation to that of the novel. For he was taking only the core idea-not much more than is expressed in the two sentences (a) and (b) above. The messages are different.

What is the message of a myth like that of Frankenstein? It is not a true story that is here being related, and nobody believes that it is. It is not even any single unequivocal moral recommendation that is being conveyed. Its function is, rather, to give interpretative patterns that can give order to the perceived world. It makes something in the world understandable. We will have to look at these patterns in detail. The advantage of taking such mythical components in our modern rational culture seriously, is that the corresponding interpretative patterns can be discussed, and thus they make possible a discussion on a level below that of moral principles, rules and value systems, namely on the level where the problem is perceived, ordered, and constituted as a problem. By the time we enter a moral discussion about questions like "Is it morally wrong to change the genetic sequence of an organism $A$ in the manner X?" the problem to be discussed is already formulated. It is already a problem of a certain type.

One stumbling-block remains: If a scientific experiment is to be morally assessed on the basis of such marginalized, chaotic mythical connotations, how could our discussion of this matter still claim to be rational? From the point of view of established rationality there is a strong temptation simply to refuse any discussions on this level. As Willard 
Gaylin argued, the "Frankenstein factor" is a frequent element in discussions about recombinant DNA, and it evokes an anti-technological bias. It is fed by irrational fears, maintained by popular imagery, and can only distort a rational climate for discussion. This factor should therefore be eliminated. 15 But how could this be done? If our claim is not completely false that the very structure of the ethical problem of DNA research is constituted in our society with the help of the Frankenstein myth, then to overlook this aspect of the process would itself be to accept a serious handicap to rational discussion itself. The community would have to cope with the corresponding moral problems without knowing how these problems were formulated.

Can we embrace a more positive approach to the mythological dimension? Do the problems here at issue show that it is no longer selfevident that there is only one type of "modern" rationality? We have, to paraphrase G. Böhme, the perceptive advantage that comes from living in a time in which an epoch has been left behind. ${ }^{16}$ If the programme of the modern epoch has been, since Francis Bacon, the systematic generation of knowledge and its application in technology for human ends, it was possibly the accompanying fear of that epoch that one might know too much, know things man ought not to know. The myths of Faust, the Sorcerer's Apprentice and Frankenstein all share in the motif of forbidden knowledge. They are myths of modernity, and belong to the Baconian programme as its shadow.

\section{Perceptive contexts}

We can now try to combine together the above elements in order to sketch a model of the way science is perceived in the public arena. I will use in my argument the concept of perceptive context by which I shall mean a milieu of problems, programmes and interpretative patterns wherein a certain event gains significance.

As we have seen, the border between different perceptive contexts does not necessarily coincide with the (institutional) borderline between the scientific community and the public. The scientific community, like the public as a whole, contains people with different perceptive contexts, and some scientists may take the same critical view of the eyeless experiment as do members of the public. The qualification of the fruit fly experiment as "Frankensteinian" originated from a scientist not belonging 
to the Gehring group. And there were voices in the public who took up this qualification and made it serve the function of a moral condemnation of the experiment. ${ }^{17}$ Other voices in the public, on the other hand, shared the perceptive context of the scientists involved in the gene experiments.

The different perceptive contexts are connected by a common object of perception; the electron microphotograph of the transformed Drosophi$l a$ head. This was reproduced dozens of times in journals, newspapers and magazines, and it was the common reference-point of distinct perceptive contexts. There were other microphotographs as well, documents of the events and manipulations leading to the abnormal fly. We could therefore say that these events and manipulations serve as a connecting object of perception. But these events could themselves be perceived directly only by the experimenters themselves, not even by all members of the laboratory. A great deal of work was invested in documenting their manipulations in such a way as to present the experiment in a way that could be grasped by the wider community. The documents acted as common objects of perception; it was the goal of their production to act in this fashion.

These documents are perceived, interpreted and integrated into the network of problems and programmes by different perceptive contexts in different ways, and our example shows how far apart these different significations can be. There is a strikingly radical dissociation between two main perceptive contexts, which I shall call the context of a "critical public" and the "scientific" context, respectively (in full awareness of the simplification this involves).

To the critical public the pictures of the Drosophila are pictures of a monster; in the scientific auditorium they are proofs of a successful experiment. These two expressions indicate the main interpretative logic in the two perceptive contexts. Both, the "monster" and the "proof" are interpretative patterns which stand in a close connection to the problems and programmes that constitute the respective contexts. Each presupposes a substantial background in order to be meaningful. A monster is a malformed organism constructed by mad (or otherwise misguided) scientists or engineers and possibly able to become dangerous. Frankenstein's nameless creature is the prototype thereof. The proof, on the other hand, is the pattern giving meaning to the same representations in the scientific perceptive context. It presupposes a background of developing theory, 
wherein hypotheses can be formulated and tests can be made. Specifically, the hypothesis tested here with the Drosophila experiment was whether eyeless acts as a "master control gene" in the cascade of molecular interactions and biochemical processes within the larva, leading phenotypically to the development of functional eyes. In other words, if the gene called eyeless functions as a main switch to turn on the whole machinery of genes, enzymes, metabolites, regulative proteins, etc., then an activation of eyeless in places of the larva where it normally stays silent, should lead to the formation of ectopic eyes. And this is precisely what has been observed. The monster and the proof are the same fly, the same object perceived, but they are completely different things for the corresponding perceiving subjects.

By the term 'programme' I mean quite generally plans of what is to be done. ${ }^{18}$ In the perceptive context of the critical public there is an expectation (or fear) that science will produce extreme examples which will be such as to unmask a tendency within the whole enterprise of scientific research. The photograph of the Drosophila monster is utilized as an especially clear symbolic example standing for more than simply the portrayed recombinant fruit fly. The fly with its ectopic eyes represents all of genetic engineering, even the whole of molecular biology. In the scientific context, on the other hand, there is a programme of measuring, of collecting data. The photograph of the Drosophila is translated into a set of sentences that can be incorporated into the body of knowledge. The information contained in the photo is joined to the results of other scientific operations. The corresponding knowledge will be incorporated into textbooks; it will be updated and further research planned. Each successful experiment gives rise to a variety of new research questions and hypotheses.

The term background of issues is used to describe a 'problem' seen as urgent. In the perceptive context of the critical public the alienated relationship between man and nature, the ecological problems of contemporary scientific and technological society are seen as being of importance. The right of man to use nature is questioned and consequently the dignity of the animal subject is considered not negligible. How is it to be such a recombinant fly? Does it suffer? Has a fly the right not to be manipulated in such a way? The background problems of the scientific context, in contrast, arise from gaps in our knowledge about how a 
complex organism develops, how it succeeds in organizing itself from the zygote to an adult fly. Problems lie also in other dimensions: the evolution of eyes in the different phyla of the animal kingdom. Problems can also be seen in the area of philosophy: how should we imagine the functional role of genes in the cell-as an essence of life, a coded blueprint of the animal, or as interactive systemic partners with other cell components involved in cascades of biochemical reactions?

\begin{tabular}{l|l|l|} 
& \multicolumn{2}{|c|}{ perceptive contexts } \\
\hline interpretative pattern & scientific public & critical public \\
programme & $\begin{array}{l}\text { measurement, } \\
\text { data collection } \\
\text { (informative value) }\end{array}$ & $\begin{array}{l}\text { monster } \\
\text { (symbolic value) }\end{array}$ \\
problem & missing knowledge & $\begin{array}{l}\text { ecological crisis } \\
\text { animals as sentient } \\
\text { subjects }\end{array}$ \\
\hline
\end{tabular}

Fig. 2: The elements of perceptive contexts. Two groups of people perceiving the same recombinant fruit fly.

The model here outlined in only preliminary fashion (see Fig. 2) could perhaps help to understand how a situation can emerge wherein an experiment is seen as scandalous, forbidden, etc. in one perceptive context and as a major breakthrough in another. The described situation reveals a communicative crisis of contemporary science. The two perceptive contexts lead to incommensurable perspectives. Arguments can only rarely be understood by both sides, and consequently moral discourse is blocked. My impression is that the last word in this case has not yet been spoken. We need a fundamental reflection on perceptive contexts and on the deficiencies in each.

\section{Another Frankensteinian ethic}

A completely different approach to the problem of monstrosity is offered by Mary Shelley's classic novel. There, the processes that lead to 
the strange experimentation of the young physician Victor Frankenstein in his solitary laboratory are made transparent.

There is a detailed description of all the alienating events that allow and encourage Victor to plan and execute such a horrible project. Both his father and Elizabeth are uninterested in his arduous studies of Agrippa and Albertus Magnus. "My dreams were therefore undisturbed by reality."(23)19 In this situation of intellectual loneliness he took up the goal of finding "the elixir of life": "what glory would attend the discovery, if I could banish disease from the human frame, and render man invulnerable to any but a violent death!" (ibid.)

During two years of study in his chemical laboratory at Ingolstadt he "paid no visit to Geneva" (32), where his family and friends lived. And for purely technical reasons he decided to make his key experiment of "bestowing animation upon lifeless matter" (34) with a being of abnormal size:

As the minuteness of the parts formed a great hindrance to my speed, I resolved, contrary to my first intention, to make the being of a gigantic stature; that is to say, about eight feet in height, and proportionably large. (35)

He collected bones and bodies from the charnel houses and worked with these in his cell at the top of the house. The summer months passed while he was thus engaged.

It was a most beautiful season; never did the fields bestow a more plentiful harvest, or the vines yield a more luxuriant vintage: but my eyes were insensible to the charms of nature. (37)

These hints at Victor's insensibility are frequent. The dramatic core of the novel is the failing relationship between Victor and his creature. Victor's first reaction, after the creature opened his eyes, was to run away. "Unable to endure the aspect of the being I had created, I rushed out of the room" (39).

Only then did he begin to see his creature as a "monster" (or a "fiend," "devil," "wretch"). Perception changed. In the beginning he had selected the creature's features as "beautiful," but after the animation and after his flight from his own creation he saw it as "miserable." The whole story following that act of creation is the drama of Victor Frankenstein's flight from the relationship with his creation. And because of his appearance the creature could find no human relationship with any other human 
being either (except the blind old man in the cottage). These continuous frustrations produced in the creature a strong and hate-filled desire for revenge-a revenge not against man in general but against his creator.

The essence of Shelley's analysis can, I think, be formulated as follows: monstrosity is a consequence of dissociation, dissociation in central human relationships. It is even possible to see the figure of the creature as a "Doppelgänger" of the scientist Frankenstein.

\section{Conclusions}

From the Shelleyan point of view the offence of the fruit-fly experiment would not be its definable monstrosity and its illegitimacy, but the dissociation of the two perceptive contexts and the difficulty of communication between them. From a non-dissociated perspective, both patterns of interpreting this experiment would have mixed in some elements of the other: the scientific arena would not only see the fly as a proof of its theories but also as a symbol leading to a critical reflection about its own goals and about the cultural backgrounds of a science which remain unquestioned only for the scientists themselves. And the critical public would see not only the monster in the portrait, but would also gain insights into the complexity of organic development and a new respect for the ingenuity of nature.

A non-alienated science might perhaps have other cultural ideals and would consequently develop other research preferences. We can only speculate what kind of experiments a developmental biology would prefer to make and how it would communicate them to the public if the situation of dissociated signification was overcome.

To conclude, the analysis of a mythical term like "Frankensteinian" can take us to the heart of the ethical problem of immorality in scientific and technological progress. The term was introduced, almost accidentally, to describe a single experiment, but it is quite generally revealing, and I am sure I have not exhausted its significance with my few remarks in this essay.

What are "monsters"? The word is built from the latin verb monstrare: to show. If we perceive something as "monstrous," this fact shows something. Monsters are perceptive indicators. One thing indicated is the dissociation of relationships between the scientists working in their own perceptive framework. The other is the problematical relationship of 
modern science to its objects. Nature is perceived in a very artificial setting-as a mere object of research. To be aware of this does not lead to a moral condemnation of the individual genetic engineers, but to a discussion of the alienated relationship between man and nature. In such a reflective undertaking at least some of the researchers could be won as partners, not as adversaries. The ideal relationship to nature has not yet been found. I am sure, it will contain many facets and science will find a place therein. ${ }^{20}$

University of Basel

Christoph Rehmann-Sutter

\section{NOTES}

1. The article by Natalie Angier in the International Herald Tribune (March 25-26, 1995) took its title from a quotation of the fruity-fly neuroscientist Charles Zuker "This is Frankensteinian science at its best" appearing in the text. Nearly the same text appeared earlier under another title in The New York Times (March 24, 1995, p. 1). The German Die Woche also used the portrait on its front page with the legend: "Frankenstein und die Fruchtfliege" (7. April 1995). The Italian magazine Panorama (Milano) made the same allusions in the title of the report "Mostri per bene" (April 28, 1995), 216-19.

2. G. Halder, P. Callaerts and W. J. Gehring: "Induction of Ectopic Eyes by Targeted Expression of the eyeless Gene in Drosophila," Science 267 (1995), 1788-92. Cf. the commentary of Marcia Barinaga in the same issue, p. 1766f.

3. Natalie Angier (see note 1, above); Georg Halder, Walter J. Gehring, personal communications.

4. Albert J. Lavalley: "The Stage and Film Children of Frankenstein: A Survey," in George Levine \& U. C. Knoepflmacher (eds.): The Endurance of Frankenstein: Essays on Mary Shelley's Novel (Berkeley, CA: University of California Press, 1979), pp. 243-89.

5. The film is documented in detail by Richard J. Anobile (ed.): Frankenstein, (London: Pan Books, 1974).

6. Cf. Gernot Böhme: "At the End of the Baconian Age," in his Coping with Science, (Boulder, CO: Westview Press, 1992), pp. 1-17.

Anobile, op. cit., pp. 77 and 103f. Frankenstein: "Dr. Waldman, I learned a great deal from you at the university about the violet ray, the ultraviolet ray which you said was the highest color in the spectrum.-You were wrong. Here in this machinery I have gone beyond that.- I have discovered the great ray that first brought life into the world." And later: "Dangerous! Poor old Waldman. Have you never wanted to do anything that was dangerous?-Where should we be if nobody tried to find out what lies beyond?-Have you never wanted to look beyond the clouds and the stars and to know what causes the trees to bud? And what changes darkness into light?-But if you talk like that, people call you crazy."

7. Cf. Christoph Rehmann-Sutter and Adrian Vatter: "Risk Communication and the Ethos of Democracy," in: Ad van Dommelen (ed.): Coping With Deliberate Release: The 
Limits of Risk Assessment (Tilburg, Netherlands: International Centre for Human and Public Affairs, 1996), pp. 207-26.

8. H. L. A. Hart: Law, Liberty, and Morality (Oxford: Oxford University Press, 1963).

9. A good modern edition is that of Marilyn Butler in The World's Classics series (Oxford: Oxford University Press, 1994).

10. See the enormous list compiled by Donald F. Glut: The Frankenstein Catalog, (Jefferson, NC: McFarland, 1984).

11. Chris Baldick: In Frankenstein's Shadow: Myth, Monstrosity, and NineteenthCentury Writing (Oxford: Clarendon Press, 1987), p. 3.

12. Ibid., p. 1.

13. Zygmunt Bauman: Modernity and Ambivalence (Cambridge: Polity Press, 1991).

14. Claude Lévi-Strauss: "The Structural Study of Myth," in: Thomas A. Seboek (ed.): Myth: A symposium (Bloomington, IN: Indiana University Press, 1958), p. 85.

15. Willard Gaylin: "The Frankenstein Factor," The New England Journal of Medicine 297 (1977), 665-67.

16. G. Böhme, op. cit.

17. Another example of a scientists in the Frankensteinian perceptive context is Ernst Peter Fischer's essay "Wohin führt uns die Fliege mit den vierzehn Augen," Die Weltwoche (6 April 1995).

18. My trichotomy of "interpretive patterns, programmes, and problems" is related to Hermann Schmitz's explanation of subjective facts as "Sachverhalte, Programmeme und Probleme" in his phenomenological philosophy (Der unerschöpfliche Gegenstand [Bonn: Bouvier, 1990]).

19. Page numbers in brackets refer to the Butler edition of Mary Shelley's Frankenstein (cited in n. 9, above).

20. I am thankful to the editors of this issue of The Monist for helpful comments and to Susanne Flister and Luzia Sutter Rehmann for many recommendations. Elisabeth Bronfen and William Keegan helped me to improve the English manuscript. My work was supported by the "Sondermassnahmen des Bundes zur Förderung des akademischen Nachwuchses." 